\title{
Gastric Cardia Cancer: How Much Is It from Fat?
}

\author{
Preetika Sinh $\cdot$ Prateek Sharma
}

Published online: 23 August 2012

(C) Springer Science+Business Media, LLC 2012

The overall age-adjusted incidence of gastric cancer has decreased in the United States from 11.7 to 7.1 persons per 100,000 from 1975 to 2008 according to the surveillance epidemiology and end results (SEER-9) database [1]. Similar trends have been observed worldwide. Although the incidence of gastric non-cardia adenocarcinoma (GNCA) has decreased worldwide the incidence of gastric cardia adenocarcinoma (GCA) has steadily increased over the last three to four decades along with a rise in esophageal adenocarcinoma (EAC) incidence [2, 3].

It is possible that the incidence of GCA has increased due to better understanding and appropriate classification of distal esophageal and GCA rather than a true increase in cancer incidence rate [4]. Current studies, however, are not completely devoid of the error of misclassification and hence concluding that the increase reflects a prior false underestimation is not completely justified. There is room for error even in studies that have selected patients based on standardized classifications. Various studies have used the International Statistical Classification of Diseases and Related Health Problems (ICD-9) and International Classification of Diseases for Oncology (ICD-O) codes [5-7]. Misclassification in the ICD-9 coding system could lead to incorrect estimation of cancer incidence (Table 1). First, EAC and cardio-esophageal junction cancers were classified under one group (ICD-9-151.0). Second, GCA could be misclassified under "unspecified gastric cancers" (ICD-9-151.9) or "overlap sites of stomach" (ICD-9151.8) [8]. In the ICD-O $2 / 3$ system GCA tumors are

P. Sinh $(\bowtie) \cdot$ P. Sharma

Division of Gastroenterology and Hepatology, Veterans' Affairs

Medical Center, University of Kansas School of Medicine,

Kansas City, MO, USA

e-mail: psinh@kumc.edu classified under C16.0 but they could be incorrectly labeled as "overlapping lesions of esophageal cancer" (C15.8) [9] (Table 1). Nyrén et al. in 1999 studied the possibility of misclassification in the Swedish cancer registry from 1989 and 1994 and reported that the incidence of GCA could be $45 \%$ higher or $15 \%$ lower than that reported [10].

The Siewert classification sorts tumors as esophageal tumor (type I), true cardia tumor (type II) and subcardial tumor (types III). This is based on the location of the cancer with respect to the cardia, which is defined as oral end of the typical longitudinal gastric mucosa folds. This might be a better way of differentiating junctional cancers [11] (Table 2; Fig. 1).

\section{Obesity as a Risk Factor for Cardia Cancer}

Among the risks factors for EAC and GCA, obesity stands out as an important modifiable factor (Table 3). The prevalence of obesity has increased from 13 to $32 \%$ between the 1960s and 2004. Currently, $68 \%$ of US adults aged 20 and over are overweight or obese and $34 \%$ are obese [12]. With the rise in the epidemic of obesity in the Western world there has been an increase in the incidence of GCA. One study calculated that the attributable risk percentage of GCA due to obesity has increased steadily in the United States to 21 and $10 \%$ in men and women, respectively [13].

Several case control studies and meta-analysis have shown a positive association between higher BMI, ECA and GCA. The association appears to be much stronger for EAC. A UK-based case-control study in 2005 showed a positive association between BMI $>25 \mathrm{~kg} / \mathrm{m}^{2}$ and EAC (OR 1.67, $95 \%$ CI 1.22-2.30), and GCA (OR 1.46, $95 \%$ CI $0.98-2.18)$. Of note the data for GCA was not 
Table 1 International Classification of Diseases for Oncology (ICD-O) coding for stomach and esophageal cancer

\begin{tabular}{ll}
\hline ICD & Term \\
code
\end{tabular}

ICD-9 (2009) stomach cancer

151 Malignant neoplasm of stomach

$151.0 \quad$ Cardia

Cardiac orifice

Cardio-esophageal junction

$151.1 \quad$ Pylorus

151.2 Pyloric antrum

151.3 Fundus

151.4 Body of stomach

151.5 Lesser curvature

151.6 Greater curvature

151.8 Other specified sites of stomach

Anterior wall not classifiable

Posterior wall not classifiable

Malignant neoplasm of contiguous or overlapping sites of stomach whose point of origin cannot be determined

ICD-O 2/3 stomach cancer

C16.0 Cardia, NOS

C16.1 Fundus of stomach

C16.2 Body of stomach

C16.3 Gastric antrum

C16.4 Pylorus

C16.5 Lesser curvature of stomach, NOS

C16.6 (Not classifiable to C16.1-C16.4)

C16.8 Greater curvature of stomach, NOS

C16.9 (Not classifiable to C16.1-C16.4)

Overlapping lesion of stomach

Stomach, NOS

ICD-O 2/3 esophageal cancer

C15.0 Cervical esophagus

C15.1 Thoracic esophagus

C15.2 Abdominal esophagus

C15.3 Upper third of esophagus

C15.4 Middle third of esophagus

C15.5 Lower third of esophagus

C15.8 Overlapping lesion of esophagus

C15.9 Esophagus, NOS

statistically significant [14]. Several other case control and population-based studies have shown similar association. In 2006, a review of two cohort and 12 case-control studies by Kubo et al. [15] showed that there was a weak association between BMI and GCA (OR 1.5, 95 \% CI 1.3-1.8, $\left.P_{\text {heterogeneity }}=0.38\right)$. A Netherlands-based study showed that the relative risk (RR) for GCA in overweight (BMI $25-29.9 \mathrm{~kg} / \mathrm{m}^{2}$ ) and obese (BMI $\geq 30 \mathrm{~kg} / \mathrm{m}^{2}$ ) subjects was 1.32 (95\% CI 0.94-1.85) and 2.73 (95\% CI 1.56-4.79),
Table 2 Siewert classification

\begin{tabular}{ll}
\hline $\begin{array}{l}\text { Siewert } \\
\text { classification } \\
\text { type }\end{array}$ & Description \\
\hline Type I & $\begin{array}{l}\text { Adenocarcinoma of the distal esophagus, which } \\
\text { usually arises from an area with specialized } \\
\text { metaplasia of the esophagus (i.e. Barrett's } \\
\text { esophagus) and may infiltrate the esophagogastric } \\
\text { junction from above }\end{array}$ \\
Type II & $\begin{array}{l}\text { True carcinoma of the cardia arising immediately at } \\
\text { the esophagogastric junction } \\
\text { Type III }\end{array}$ \\
& $\begin{array}{l}\text { esophagogastric junction and distal esophagus } \\
\text { from below }\end{array}$ \\
\hline
\end{tabular}

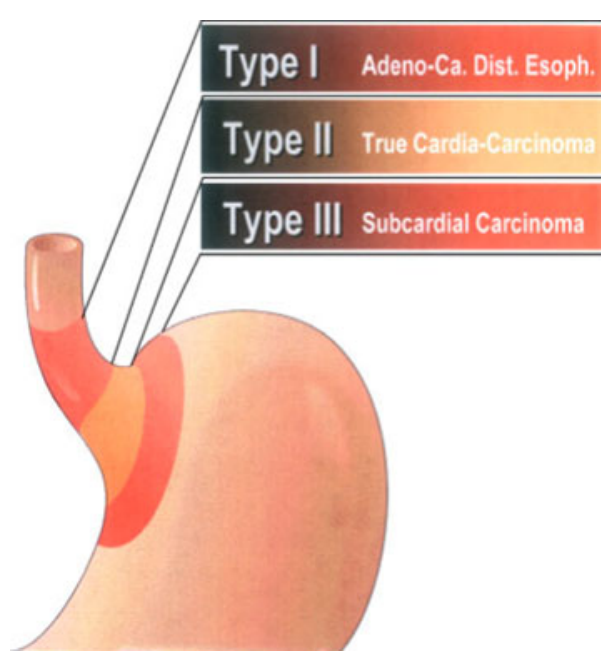

Fig. 1 Topographic-anatomical classification of adenocarcinoma of gastro-esophageal junction based on their relationship to the cardia, which is defined as the oral end of the typical longitudinal gastric mucosa folds (reproduced with permission from Siewert et al. [1])

respectively, as compared to normal weight subjects (BMI 20-24.9 kg/m ${ }^{2}$ ). This study also showed that an increase in BMI in adulthood since age 20 was associated with significantly increased risk of ECA and GCA $\left(P_{\text {trend }} 0.001\right.$ and 0.02, respectively) [16]. A US-population-based cohort study of half a billion people from 1995-1996 to 2003 was consistent with the earlier case-control studies and reported a hazard ratio (HR) of 2.46 (95\% CI 1.6-3.8) for GCA with $\mathrm{BMI} \geq 35 \mathrm{~kg} / \mathrm{m}^{2}$ as compared to BMI of $18.5-25 \mathrm{~kg} / \mathrm{m}^{2}$. In EAC, where the HR for BMI $\geq 35 \mathrm{~kg} / \mathrm{m}^{2}$ was 2.27 (95\% CI 1.44-3.59) they even found that higher BMI was associated with increased risk, even in the normal BMI range [8]. The above data clearly showed a strong association of obesity and GCA in a dose-dependent manner.

It is interesting to note that the racial distribution of obesity and GCA do not follow the same trends. Obesity has increased in the African-American population in the United States whereas GCA is more common in white men 
Table 3 Risk factors for esophageal adenocarcinoma and gastric cardia cancers

\begin{tabular}{ll}
\hline EAC & GCA \\
\hline Risk factors & \\
Barrett's esophagus [31] & Barrett's esophagus [31] \\
GERD [32] & GERD [32] \\
White race [3] & White race [3] \\
Male sex [3] & Male sex [3] \\
Obesity [14] & Obesity [14] \\
Tobacco [33, 34] & Tobacco [33, 34] \\
Protective factors & \\
NSAIDs [35] & Cag A+ strain of H. pylori ${ }^{\mathrm{a}}$ \\
Vitamin C [36] & \\
$\beta$-carotene [36] & \\
Raw fruits and vegetables [36] & \\
Cag A+ strain of H. pylori ${ }^{\mathrm{a}}$ [37, 38] &
\end{tabular}

${ }^{a}$ Controversial

[12]. It is possible that other measures of assessing obesity like visceral body fat, waist to height ratio (WHR) or waist circumference (WC) better correlate with and hence help explain the mechanism behind obesity-related increase in cancer incidence [7]. A nested case-control study by Corley et al. [17] showed that abdominal diameter was associated with increase of EAC independent of BMI. A similar association was observed but was not statistically significant in GCA (OR 1.28, $95 \%$ CI 0.38-4.25; diameter $\geq 25$ vs. $<20 \mathrm{~cm}$ ) in this study. A population-based cohort study from O'Doherty et al. [7] showed that WC was associated with increase in GCA and EAC. WHR was positively associated with EAC risk only and this association was seen even in patients with normal BMI $(18.5$ to $<25 \mathrm{~kg} /$ $\mathrm{m}^{2}$ ). A report from Australia also supported the finding of increase in risk of GCA and EAC with increase in WC. They reported a HR of 1.46 (95\% CI 1.05-2.04) per $10 \mathrm{~cm}$ increase in WC for GCA and EAC in a cohort of around 41,000 people between the ages of 25 and 75 years observed over 11 years [6].

\section{What Does the Current Study Add?}

The current article from Cho et al. [18] from Korea is in concordance with the BMI data observed in prior studies from the Western population. Data from prior Asian studies have been inconsistent with regard to the incidence of GCA. Some showed an increase in incidence in Japanese, Chinese, Korean, Singaporean and South Indian populations while others showed no change [19-24]. A metaanalysis by Corley et al. showed that there was no clear association between GCA and obesity in the Asian population and one study had even showed negative correlation $[15,25]$. This latest Korean study however focuses on the difference in risk factors for GCA and GNCA and shows a positive association of obesity with GCA in the Korean population even when measured by Western standards [18].

The role of Helicobacter pylori and cagA+ strains in GCA has been controversial. Some studies show no association with GCA while others show a protective effect and even argue that the increase in incidence of GCA and ECA might be related to a decrease in the prevalence and hence protective effect of $H$. pylori [26, 27]. Cases from Cho et al. study did not show any difference between GCA and GNCA in $H$. pylori detection. Evaluation of the cagA+ strain might have been more helpful as compared to histological detection of $H$. pylori in post resection specimens. Misclassification as mentioned above has always been an issue in GCA cases. The authors classified cases based on the location of tumor in surgical specimens, which is likely to be more accurate than the ICD classification. Of note, although the tumor classification was not totally consistent with the Siewert's classification (with respect to distance from GEJ), it appears more reasonable with less chances of missed or misclassified GCA.

In conclusion, GCA and EAC are associated with obesity as measured by BMI and additional parameters like WC and visceral fat [7, 28]. The rising incidence of these cancers has been associated with the epidemic of obesity, especially in the Western world; however, race and age cannot completely explain the trend. Other parameters of measuring obesity like $\mathrm{WC}$ and visceral fat might have a better chance of explaining the correlation. The underlying mechanism is unclear. It has been shown that various adipokines and hormones like $\mathrm{TNF}-\alpha$, adiponectin, leptin, insulin, and interleukin-6 may play a role in development of EAC, Barrett's esophagus and GCA [28-30].

It has also been shown that not only does obesity increase the risk of cancer, the increase in BMI with age in adulthood is associated with increase in incidence of GCA and ECA [16]. Hence it would be interesting to see if weight reduction leads to a decrease in incidence of GAC or EAC. Large cohort studies are needed to assess this effect.

\section{References}

1. National Cancer Institute. SEER stat fact sheets: stomach. 2012. Available at: http://seer.cancer.gov/statfacts/html/stomach.html\# incidence-mortality. Accessed 20 July 2012.

2. Blot WJ, Devesa SS, Kneller RW, Fraumeni JF Jr. Rising incidence of adenocarcinoma of the esophagus and gastric cardia. JAMA. 1991;265:1287-1289.

3. Botterweck AA, Schouten LJ, Volovics A, Dorant E, van Den Brandt PA. Trends in incidence of adenocarcinoma of the 
oesophagus and gastric cardia in ten European countries. Int $J$ Epidemiol. 2000;29:645-654.

4. El-Serag HB, Mason AC, Petersen N, Key CR. Epidemiological differences between adenocarcinoma of the oesophagus and adenocarcinoma of the gastric cardia in the USA. Gut. 2002;50: 368-372.

5. MacInnis RJ, English DR, Hopper JL, Giles GG. Body size and composition and the risk of gastric and oesophageal adenocarcinoma. Int J Cancer J Int Cancer. 2006;118:2628-2631.

6. O'Doherty MG, Freedman ND, Hollenbeck AR, Schatzkin A, Abnet CC. A prospective cohort study of obesity and risk of oesophageal and gastric adenocarcinoma in the NIH-AARP Diet and Health Study. Gut. 2011.

7. Abnet CC, Freedman ND, Hollenbeck AR, Fraumeni JF Jr, Leitzmann M, Schatzkin A. A prospective study of BMI and risk of oesophageal and gastric adenocarcinoma. Eur J Cancer. 2008; 44:465-471.

8. The International Classification of Diseases, 9th revision. Clinical Modification, 2nd ed. City: Public Health Service, US Government Printing Office; 1980:80-1260.

9. International Classification of Diseases for Oncology. Geneva: World Health Organization; 1976.

10. Ekstrom AM, Signorello LB, Hansson LE, Bergstrom R, Lindgren A, Nyren O. Evaluating gastric cancer misclassification: a potential explanation for the rise in cardia cancer incidence. J Natl Cancer Inst. 1999;91:786-790.

11. Siewert JR, Feith M, Stein HJ. Biologic and clinical variations of adenocarcinoma at the esophagogastric junction: relevance of a topographic-anatomic subclassification. J Surg Oncol (Semin). 2005;90:139-146; discussion 146.

12. Wang Y, Beydoun MA. The obesity epidemic in the United States-gender, age, socioeconomic, racial/ethnic, and geographic characteristics: a systematic review and meta-regression analysis. Epidemiol Rev. 2007;29:6-28.

13. Polednak AP. Estimating the number of US incident cancers attributable to obesity and the impact on temporal trends in incidence rates for obesity-related cancers. Cancer Detect Prev. 2008;32:190-199.

14. Lindblad M, Rodriguez LA, Lagergren J. Body mass, tobacco and alcohol and risk of esophageal, gastric cardia, and gastric noncardia adenocarcinoma among men and women in a nested casecontrol study. Cancer Causes Control (CCC). 2005;16:285-294.

15. Kubo A, Corley DA. Body mass index and adenocarcinomas of the esophagus or gastric cardia: a systematic review and metaanalysis. Cancer Epidemiol Biomarkers Prev. 2006;15:872-878.

16. Merry AH, Schouten LJ, Goldbohm RA, van den Brandt PA. Body mass index, height and risk of adenocarcinoma of the oesophagus and gastric cardia: a prospective cohort study. Gut. 2007;56:1503-1511.

17. Corley DA, Kubo A, Zhao W. Abdominal obesity and the risk of esophageal and gastric cardia carcinomas. Cancer Epidemiol Biomarkers Prev. 2008;17:352-358.

18. Cho Y, Lee DH, Oh HS, et al. Higher prevalence of obesity in gastric cardia adenocarcinoma compared to gastric non-cardia adenocarcinoma. Dig Dis Sci. 2012. (Epub ahead of print). doi: 10.1007/s10620-012-2095-6.

19. Deans C, Yeo M, Soe M, Shabbir A, Ti T, So J. Cancer of the gastric cardia is rising in incidence in an Asian population and is associated with adverse outcome. World J Surg. 2011;35: 617-624.

20. Kusano C, Gotoda T, Khor CJ, et al. Changing trends in the proportion of adenocarcinoma of the esophagogastric junction in a large tertiary referral center in Japan. $J$ Gastroenterol Hepatol. 2008;23:1662-1665.

21. Tony J, Kumar SK, Thomas V. Time trends and pathological profile of carcinoma lower oesophagus and gastro-oesophageal junction over the last 20 years - an experience from South India. Trop Gastroenterol Off J Dig Dis Found. 2007;28:113-116.

22. Zhou Y, Zhang Z, Zhang Z, et al. A rising trend of gastric cardia cancer in Gansu Province of China. Cancer Lett. 2008;269: $18-25$.

23. Chang SS, Lu CL, Chao JY, et al. Unchanging trend of adenocarcinoma of the esophagus and gastric cardia in Taiwan: a 15-year experience in a single center. Dig Dis Sci. 2002;47:735-740.

24. Hasegawa S, Yoshikawa T, Cho H, Tsuburaya A, Kobayashi O. Is adenocarcinoma of the esophagogastric junction different between Japan and western countries? The incidence and clinicopathological features at a Japanese high-volume cancer center. World J Surg. 2009;33:95-103.

25. Zhang J, Su XQ, Wu XJ, et al. Effect of body mass index on adenocarcinoma of gastric cardia. World J Gastroenterol. 2003; 9:2658-2661.

26. Chow W-H, Blaser MJ, Blot WJ, et al. An inverse relation between cagA + strains of Helicobacter pylori infection and risk of esophageal and gastric cardia adenocarcinoma. Cancer Res. 1998;58:588-590.

27. Wu AH, Crabtree JE, Bernstein L, et al. Role of Helicobacter pylori $\mathrm{Cag} \mathrm{A}+$ strains and risk of adenocarcinoma of the stomach and esophagus. Int $J$ Cancer. 2003;103:815-821.

28. Beddy P, Howard J, McMahon C, et al. Association of visceral adiposity with oesophageal and junctional adenocarcinomas. Brit J Surg. 2010;97:1028-1034.

29. Akiyama T, Yoneda M, Maeda S, Nakajima A, Koyama S, Inamori M. Visceral obesity and the risk of Barrett's esophagus. Digestion. 2011;83:142-145.

30. Lagergren J. Influence of obesity on the risk of esophageal disorders. Nat Rev Gastroenterol Hepatol. 2011;8:340-347.

31. Cameron AJ, Lomboy CT, Pera M, Carpenter HA. Adenocarcinoma of the esophagogastric junction and Barrett's esophagus. Gastroenterology. 1995;109:1541-1546.

32. Lagergren J, Bergström R, Lindgren A, Nyrén O. Symptomatic gastroesophageal reflux as a risk factor for esophageal adenocarcinoma. N Engl J Med. 1999;340:825-831.

33. Cook MB, Kamangar F, Whiteman DC, et al. Cigarette smoking and adenocarcinomas of the esophagus and esophagogastric junction: a pooled analysis from the international BEACON consortium. J Natl Cancer Inst. 2010;102:1344-1353.

34. Tramacere I, La Vecchia C, Negri E. Tobacco smoking and esophageal and gastric cardia adenocarcinoma: a meta-analysis. Epidemiology. 2011;22:344-349.

35. Liao LM, Vaughan TL, Corley DA, et al. Nonsteroidal antiinflammatory drug use reduces risk of adenocarcinomas of the esophagus and esophagogastric junction in a pooled analysis. Gastroenterology. 2012;142:442-452, e445; quiz e422-e443.

36. Kubo A, Corley DA, Jensen CD, Kaur R. Dietary factors and the risks of oesophageal adenocarcinoma and Barrett's oesophagus. Nutr Res Rev. 2010;23:230-246.

37. Chow WH, Blaser MJ, Blot WJ, et al. An inverse relation between cagA + strains of Helicobacter pylori infection and risk of esophageal and gastric cardia adenocarcinoma. Cancer Res. 1998;58:588-590.

38. Islami F, Kamangar F. Helicobacter pylori and esophageal cancer risk: a meta-analysis. Cancer Prev Res (Phila). 2008;1:329-338. 